\title{
A systematic review of mosquito coils and passive emanators: defining recommendations for spatial repellency testing methodologies
}

\author{
Sheila B Ogoma ${ }^{1,2^{*}}$, Sarah J Moore ${ }^{1,2}$ and Marta F Maia ${ }^{1,2}$
}

\begin{abstract}
Mosquito coils, vaporizer mats and emanators confer protection against mosquito bites through the spatial action of emanated vapor or airborne pyrethroid particles. These products dominate the pest control market; therefore, it is vital to characterize mosquito responses elicited by the chemical actives and their potential for disease prevention. The aim of this review was to determine effects of mosquito coils and emanators on mosquito responses that reduce human-vector contact and to propose scientific consensus on terminologies and methodologies used for evaluation of product formats that could contain spatial chemical actives, including indoor residual spraying (IRS), long lasting insecticide treated nets (LLINs) and insecticide treated materials (ITMs). PubMed, (National Centre for Biotechnology Information (NCBI), U.S. National Library of Medicine, NIH), MEDLINE, LILAC, Cochrane library, IBECS and Armed Forces Pest Management Board Literature Retrieval System search engines were used to identify studies of pyrethroid based coils and emanators with key-words "Mosquito coils" "Mosquito emanators" and "Spatial repellents". It was concluded that there is need to improve statistical reporting of studies, and reach consensus in the methodologies and terminologies used through standardized testing guidelines. Despite differing evaluation methodologies, data showed that coils and emanators induce mortality, deterrence, repellency as well as reduce the ability of mosquitoes to feed on humans. Available data on efficacy outdoors, dose-response relationships and effective distance of coils and emanators is inadequate for developing a target product profile (TPP), which will be required for such chemicals before optimized implementation can occur for maximum benefits in disease control.
\end{abstract}

Keywords: Spatial repellents, Pyrethroids, Coils, Passive emanators, Mosquito responses

\section{Review}

Currently, control of malaria vectors relies almost entirely on indoor residual-spraying (IRS) and long-lasting insecticide-treated nets (LLINs) [1]. These vector control tools have successfully reduced mosquito population densities and malaria by targeting indoor-feeding (endophagic) and indoor-resting (endophilic) mosquitoes [2]. The most successful IRS chemical active used to date is DDT, which, in addition to killing mosquitoes, also reduces indoor mosquito densities consequently reducing malaria transmission [3-6].

\footnotetext{
* Correspondence: sogoma@ihi.or.tz

'Environmental Thematic Group, Ifakara Health Institute, P.O. Box 53, Ifakara, Morogoro, United Republic of Tanzania

${ }^{2}$ Department of Disease Control, London School of Hygiene \& Tropical Medicine, Keppel Street, London WC1E 7HT, United Kingdom
}

Literature shows that much of the success of DDT is due to excito-repellency $[4,5]$. An excito-repellent is defined as a chemical that causes insects to make undirected movements that set them apart from insecticides [7]. Excito-repellency results from insect's physical contact with chemicals on treated surfaces or with vapour particles at a distance $[8,9]$. It has been demonstrated that volatile DDT can induce neural excitement in insects [10] and importantly, it was observed that insects exposed to sub-lethal concentrations of DDT move towards the light explaining why mosquitoes are likely to quickly leave a sprayed dwelling [11]. Excito-repellency was also originally seen as a beneficial feature of pyrethroid treated bednets to reduce the probability of mosquitoes developing resistance to insecticides through lower contact with insecticides [12]. It is known that DDT and 
pyrethroids act on the voltage-gated sodium channel proteins found in insect nerve cell membranes, disrupting transmission of nerve impulses thereby causing mortality [13]. Cross resistance between DDT and pyrethroids is conferred by point mutations on the voltage gated sodium channel in mosquitoes indicating a common mode of toxic action for these insecticides on mosquitoes [14]. Mechanisms underlying host-seeking and feeding behaviours of mosquitoes are largely unknown and have been the topic of current investigations. It is known that sublethal exposure to both pyrethroids and DDT has a differing effect on insect feeding responses: pyrethroids inhibit responses to attractants while DDT increases neural sensitivity to attractive sources $[15,16]$. New advancements in the field of neurobiology have demonstrated that perception of chemicals in the environment by insects begins when compounds activate ionotropic receptors, gustatory receptors and olfactory receptors (ORs) located on the dendritic surface of chemosensory neurons of the olfactory receptor cells (ORCs) housed in a head appendage (e.g. antenna or palp) [17]. ORs recognize biologically meaningful chemical ligands, and shape responses of olfactory sensory neurons (OSNs), thus regulating many behaviors including repellency.

Repellents either activate or inhibit action of ORs interfering with the host-seeking behaviour of mosquitoes, resulting in repellency or anti-feeding [18]. A repellent pyrethroid has been shown to disrupt insect behaviour not through targeting the voltage gated sodium channel but instead inhibits the response of odorant receptors (ORs) to attractants in a similar way to para-menthane 3,8 diol and nepetalactone [18]. Repellency is a characteristic of personal protection tools such as mosquito coils, liquid vaporizers, vaporizer mats and ambient emanators [19]. These tools have been extensively studied yet they have not been promoted as formal methods for mosquito control. In 2006 the consumer market for pesticides was about $\$ 8.4$ billion, with expected double-digit annual growth mainly due to rising income levels in several developing-world markets, notably China [20]. By far the most popular segment was aerosols, at $\$ 3.6$ billion, followed by topical repellents, powders, and gels at $\$ 2$ billion. The smaller segments of mats and vaporizers accounted for $\$ 1.6$ billion and coils for $\$ 1$ billion [20]. These products are already widely used and would therefore be expected to have community uptake if they were introduced as a formal means of disease control in an integrated vector management (IVM) strategy.

In addition, due to increased need for effective vector control tools, to combat residual outdoor-biting and resting mosquitoes [21], it is timely to review studies of mosquito coils and emanators. This will enable better understanding of their mode of action and hence gain useful knowledge for development of effective spatially acting chemical products that can be used outdoors hence complement LLINs and IRS for integration into a malaria elimination strategy [22].

The main active ingredients recommended by the World Health Organization (WHO) for use in the vapour phase all belong to the pyrethroid chemical class. The most commonly used format; mosquito coils are cheap and effective but produce smoke [23] which is undesirable. Vaporizer mats are an alternative to coils. The mats contain embedded repellent active ingredients that are volatilised using an electric heating element. This need for electricity can increase product costs making them inappropriate for some rural and urban settings in low or middle-income countries.

Recently, other delivery formats that do not require heating or combustion have been developed. These are commonly known as emanators and are composed of insecticides impregnated on substrates such as paper, plastic or agarose-based gels [24,25]. Unlike coils and mats, emanators function through passive evaporation of chemical actives. These chemicals are less polar and have lower vapour pressure than conventional pyrethroids hence evaporate at ambient temperature without the need for an external source of energy. Examples of these insecticides include metofluthrin and transfluthrin.

The aim of this review was to determine effects of mosquito coils and emanators on mosquito responses that reduce human-vector contact and to propose scientific consensus on terminologies and methodologies used for evaluation of product formats that could contain spatial repellents including IRS, LLINs and insecticide treated materials (ITMs).

This review was conducted in accordance with PRISMA (Preferred Reporting Items for Systematic Reviews and Meta-Analyses) guidelines [26]. PubMed, (National Center for Biotechnology Information (NCBI), National Library of Medicine, NIH), MEDLINE, LILACS, Cochrane library, IBECS and Armed Forces Pest Management Board Literature Retrieval System were searched systematically for both field and laboratory studies that included pyrethroid based coils and/or emanators using the English key-words "Mosquito coils", "Mosquito emanators" and "Spatial repellents", between January and November 2011. In addition to journal articles, we searched reference lists of identified papers. We also checked the System for Information on Grey Literature in Europe (SIGLE) for unpublished data from sources such as conference proceedings, abstracts and there with ensured that there was no publication bias. The last search was conducted on $21^{\text {st }}$ September 2012. We were confident that the search engines we used provided almost all relevant studies of interest. Data were 
extracted from selected articles that met all study criteria using a standardized spreadsheet. The information collected included first author, year of publication, methods and design, active ingredient, dose, mosquito species, sample size, description of the control, testing conditions (experimental huts, rooms, chambers or cylinders) and the outcome measures reported with any available statistical information.

\section{Inclusion and exclusion criteria}

All publications evaluating coils and/or emanators were reviewed. However, to facilitate comparison of bioefficacy of different active ingredients across studies, the following selection scheme was employed (Figure 1): (i) laboratory and field studies were reviewed separately; (ii) only laboratory and field studies that quantified mosquito responses including biting/feeding inhibition of mosquitoes, knock-down time and percentage mortality 24 hours post-exposure to insecticides, deterrence, repellency or irritancy of insecticides were included; (iii) studies where the dose of active ingredient was not indicated were excluded, (iv) all studies where coils contained a mixture of insecticides or additives were excluded.

\section{Summaries of reported mosquito responses to coils and emanators, and suggestions for harmonization of terminologies}

Several investigators report a number of mosquito responses to airborne insecticide particles. These responses are classified into measurable indicators namely: deterrence, repellency and irritancy, biting/feeding inhibition, knock-down and mortality. Scientific discussions differentiate between mechanisms in mosquitoes leading to responses elicited in the presence of chemical actives and the outcomes quantified $[4,7,8,11]$, this review is restricted to measured behavioural endpoints or consequences and not possible mechanisms causing them.

All studies identified and included in the review evaluated formulated/optimized emanators and coils. It should be noted that comparison of pyrethrins to metofluthrin emanators is only appropriate if both actives were formulated or both were neat material (unoptimized) as effects on volatization and longevity (among other chemical properties) will be different and bias analyses. This holds true even for comparing results of the same active ingredient.

\section{Deterrence}

Airborne insecticide particles present inside and around houses create a chemical barrier that prevents mosquitoes from entering [27]. Deterrence has been measured in the field by comparing the number of mosquitoes entering houses with insecticides and those without. Coils containing pyrethrins deter between $45 \%$ and $80 \%$ mosquitoes (Table 1) and 200mg optimized metofluthrin emanators reduce mosquitoes by $>80 \%$ within the first 4 weeks of treatment [28]. However, results from these studies cannot be generalized for other spatial repellent compounds due to potential differences in product formulation i.e., optimized components for release and retention. Only one study measured dose-dependent effects of pyrethrum coils [29] and showed no correlation between the proportion of mosquitoes deterred and the dose of pyrethrum (Table 1). Reduced indoor density of mosquitoes in insecticide treated houses could

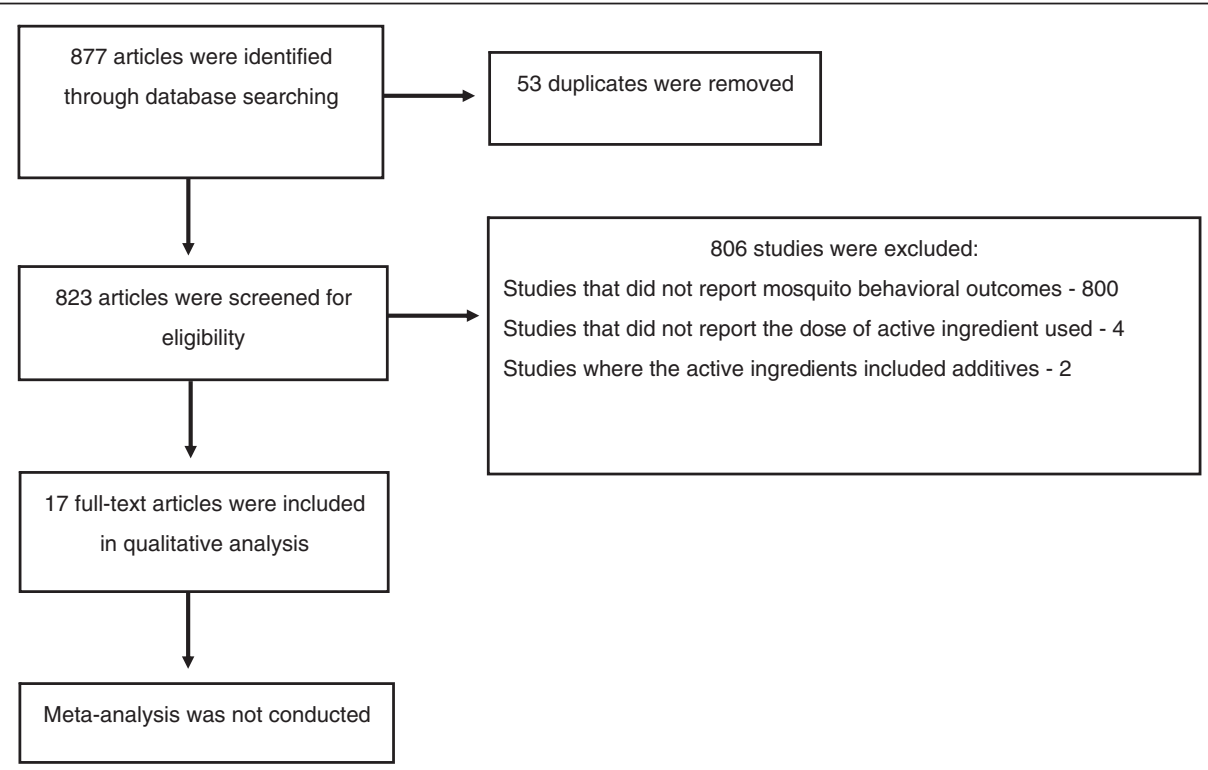

Figure $1 \mathrm{~A}$ flow diagram of the selection procedure used for the systematic review of accessible articles. 
Table 1 Mosquito behavioral reactions induced by burning coils in experimental huts

\begin{tabular}{|c|c|c|c|c|c|c|c|}
\hline $\begin{array}{l}\begin{array}{l}\text { Active } \\
\text { ingredient }\end{array} \\
\end{array}$ & $\begin{array}{l}\text { Dose } \\
\text { (w/w \%) }\end{array}$ & Vector & $\begin{array}{l}\text { Feeding } \\
\text { inhibition (\%) }\end{array}$ & $\begin{array}{l}\text { Non-Contact } \\
\text { irritancy (\%) }\end{array}$ & $\begin{array}{l}\text { Deterrence } \\
(\%)\end{array}$ & $\begin{array}{l}\text { Mortality } \\
(\%)\end{array}$ & Reference \\
\hline Pyrethrum & $0.10 \%$ & Anopheles gambiae Gillies ${ }^{a}$ & 54 & 82 & 51 & 16 & {$[29]$} \\
\hline Pyrethrum & $0.10 \%$ & Culex fatigans & 26 & 58 & 64 & 4 & [29] \\
\hline Pyrethrum & $0.10 \%$ & Mansonia uniformis & 24 & 93 & 45 & 3 & {$[29]$} \\
\hline Pyrethrum & $0.50 \%$ & Anopheles gambiae Gillies & 60 & 87 & 58 & 15 & {$[29]$} \\
\hline Pyrethrum & $0.50 \%$ & Culex fatigans & 46 & 67 & 51 & 7 & [29] \\
\hline Pyrethrum & $0.50 \%$ & Mansonia uniformis & 69 & 87 & 58 & 15 & {$[29]$} \\
\hline
\end{tabular}

${ }^{a}$ The sub species of Anopheles gambiae Gillies was not specified.

be due to the spatial action of chemical actives which interfere with the host seeking process of mosquitoes making the houses less attractive even when humans are present. In addition, mosquitoes entering treated houses are prevented from feeding. Such observations warrant further investigations of spatially acting chemicals.

\section{Repellency and irritancy}

Repellency was originally defined to refer to the distribution of insects/mosquitoes on chemically treated surfaces compared to untreated surfaces [11]. This description considers the end result of the effect of chemicals and does not account for a series of preceding behaviours exhibited by mosquitoes that lead to the final outcome. Therefore, this definition was refined to refer to movement of mosquitoes away from a source to which they would otherwise be attracted [30]. Dethier described two kinds of behaviour causing insects to sit apart from insecticide treated surfaces: [7] "taxis": immediate directional reaction, resulting in movement away from a treated surface and; 2) "orthokinesis": increased undirected activity after contact with insecticides. Both reactions reduce mosquitoes on treated surfaces $[7,8]$. These terms have been developed further to include "contact irritancy" where mosquitoes make oriented movement away from a chemical source after physical contact with insecticide treated surfaces $[3,4]$ and "non-contact irritancy", where mosquitoes move away when exposed to vapour insecticide particles usually operating at a distance. This has also been described as "spatial repellency" [4,31], or "area repellency" [32] or "non-contact disengagement" [8]. Non-contact irritancy, spatial repellency and non-contact disengagement all describe behavioural endpoints resulting from exposure to chemical emanations from coils and emanators. For purposes of clarity we propose that spatial repellency should be used as a general term to refer to the sum of mosquito behaviours produced by airborne chemicals that result in mosquitoes sitting apart from a source of stimulation [8].

"Non-contact irritancy" was measured in the field using local houses or experimental huts fitted with exit- and entry-traps [29,33-35] by comparing the proportion of mosquitoes exiting untreated and treated structures. Using this approach, studies have demonstrated an increased proportion of mosquitoes that exit earlier from huts with burning coils compared to huts which do not have coils [29]. There was a positive correlation between the proportion of mosquitoes exiting huts and the concentration of the active ingredient [29]. This indicates that the magnitude of irritancy might be dose-dependent [31]. An effective way of measuring "non-contact irritancy" is by releasing laboratory-reared mosquitoes inside experimental huts [4] and observing how fast they leave treated huts compared to control huts. This field data demonstrated good correlation with laboratory data from a high-throughput screening system (HiTSS) developed for evaluating behavioural mode of action of active ingredients [4].

\section{Biting/feeding inhibition}

Feeding or biting inhibition is where mosquitoes are prevented from biting or feeding on humans. Coils reduce the biting rate of mosquitoes (Table 1). Small amounts of insecticides [36] or repellents have been shown to interfere with the host-seeking process of disease vectors $[37,38]$. Sometimes mosquitoes land on the host but do not feed in the presence of repellent actives [39]. Therefore, the act of feeding (probing) should be quantified rather than landing rate. Only one study displayed an increase in the proportion of mosquitoes inhibited from feeding when the dose was increased [29]. In some cases even the smoke which does not contain chemicals reduces biting rate significantly compared to controls where coils are not used [40]. This warrants the need to conduct more studies with different doses of spatial chemical actives and to generate dose-response curves which will enhance better understanding of the mode of action.

The most accurate and representative method to measure feeding inhibition is through human landing catch (HLC) [41]. Some studies use guinea-pigs as bait [42], which are not proxy indicators for man. A study comparing biting inhibition on guinea pigs and man 
Table 2 Knock-down time and mortality of mosquitoes after exposure to smoke from smoldering coils

\begin{tabular}{|c|c|c|c|c|c|c|}
\hline $\begin{array}{l}\text { Active } \\
\text { ingredient }\end{array}$ & $\begin{array}{l}\text { Dose } \\
\text { (w/w \%) }\end{array}$ & Vector & $\begin{array}{l}\text { Mortality } \\
(\%)\end{array}$ & $\begin{array}{l}\text { Knock-down } \\
\text { (KT50 minutes) }\end{array}$ & Method & Reference \\
\hline Allethrin & $0.60 \%$ & Culex pipiens pallens & 0.12 & 5.1 & $70 \mathrm{~cm}^{3}$ Chamber & {$[44]$} \\
\hline Allethrin & $0.60 \%$ & Stegomyia (Aedes) aegypti & 0.72 & 3.1 & $70 \mathrm{~cm}^{3}$ Chamber & {$[44]$} \\
\hline Allethrin & $0.60 \%$ & Anopheles stephensi & 0.81 & 3.2 & $70 \mathrm{~cm}^{3}$ Chamber & [44] \\
\hline Allethrin & $0.50 \%$ & Anopheles stephensi & 33 & 9.5 & $25 \mathrm{~m}^{3}$ room & {$[42]$} \\
\hline Allethrin & $0.25 \%$ & Anopheles stephensi & 38 & 11.1 & $25^{3}$ room & [42] \\
\hline Allethrin & $0.20 \%$ & Anopheles stephensi & 25 & 11.3 & $25^{3}$ room & {$[42]$} \\
\hline Allethrin & $0.15 \%$ & Anopheles stephensi & 32 & 14.5 & $25^{3}$ room & {$[42]$} \\
\hline Allethrin & $0.50 \%$ & Stegomyia (Aedes) aegypti & 88 & 14.9 & $25^{3}$ room & {$[42]$} \\
\hline Allethrin & $0.25 \%$ & Stegomyia (Aedes) aegypti & 70 & 24.8 & $25^{3}$ room & {$[42]$} \\
\hline Allethrin & $0.20 \%$ & Stegomyia (Aedes) aegypti & 54 & 29.0 & $25^{3}$ room & {$[42]$} \\
\hline Allethrin & $0.20 \%$ & Anopheles stephensi & 49 & 4.5 & 500 mm by 300 mm cylinder & {$[42]$} \\
\hline Allethrin & $0.15 \%$ & Anopheles stephensi & 49 & 4.9 & $500 \mathrm{~mm}$ by $300 \mathrm{~mm}$ cylinder & [42] \\
\hline Allethrin & $0.10 \%$ & Anopheles stephensi & 42 & 5.5 & 500 mm by 300 mm cylinder & [42] \\
\hline Allethrin & $0.05 \%$ & Anopheles stephensi & 32 & 6.8 & 500 mm by 300 mm cylinder & {$[42]$} \\
\hline Allethrin & $0.20 \%$ & Stegomyia (Aedes) aegypti & 95 & 6.2 & 500 mm by 300 mm cylinder & {$[42]$} \\
\hline Allethrin & $0.15 \%$ & Stegomyia (Aedes) aegypti & 73 & 7.5 & 500 mm by 300 mm cylinder & {$[42]$} \\
\hline Allethrin & $0.10 \%$ & Stegomyia (Aedes) aegypti & 54 & 10.0 & 500 mm by 300 mm cylinder & {$[42]$} \\
\hline Allethrin & $0.05 \%$ & Stegomyia (Aedes) aegypti & 26 & 16.0 & 500 mm by 300 mm cylinder & {$[42]$} \\
\hline d- allethrin & $0.30 \%$ & Culex pipiens pallens & 0.15 & 3.8 & $70 \mathrm{~cm}^{3}$ Chamber & {$[44]$} \\
\hline d- allethrin & $2.00 \%$ & Stegomyia (Aedes) aegypti & 0.316 & 1.57 & $2 m^{3}$ Peet-Grady chamber & [45] \\
\hline d- allethrin & $2.00 \%$ & Culex quinquefasciatus & 0.491 & 0.98 & $2 m^{3}$ Peet-Grady chamber & {$[45]$} \\
\hline d- allethrin & $2.00 \%$ & Anopheles stephensi & 0.674 & 1.94 & $2 m^{3}$ Peet-Grady chamber & {$[45]$} \\
\hline d- allethrin & $0.30 \%$ & Anopheles stephensi & 0.81 & 2.4 & $70 \mathrm{~cm}^{3}$ Chamber & {$[44]$} \\
\hline d- allethrin & $0.30 \%$ & Stegomyia (Aedes) aegypti & 0.84 & 2.4 & $70 \mathrm{~cm}^{3}$ Chamber & {$[44]$} \\
\hline $\mathrm{d}, \mathrm{d}$-T-plarethrin & $0.10 \%$ & Stegomyia (Aedes) aegypti & 0.22 & 171 & $25 \mathrm{~m}^{3}$ room & [46] \\
\hline d,d-T-plarethrin & $0.10 \%$ & Stegomyia (Aedes) aegypti & 0.24 & 120 & $25 \mathrm{~m}^{3}$ room & {$[46]$} \\
\hline d,d-T-plarethrin & $0.10 \%$ & Culex pipiens quinquefasciatus & 0.25 & 108 & $25 \mathrm{~m}^{3}$ room & [46] \\
\hline d,d-T-plarethrin & $0.15 \%$ & Stegomyia (Aedes) aegypti & 0.25 & 140 & $25 \mathrm{~m}^{3}$ room & [46] \\
\hline d,d-T-plarethrin & $0.20 \%$ & Stegomyia (Aedes) aegypti & 0.28 & 130 & $25 \mathrm{~m}^{3}$ room & {$[46]$} \\
\hline d,d-T-plarethrin & $0.10 \%$ & Culex pipiens quinquefasciatus & 0.3 & 55 & $25 \mathrm{~m}^{3}$ room & {$[46]$} \\
\hline d,d-T-plarethrin & $0.15 \%$ & Stegomyia (Aedes) aegypti & 0.3 & 100 & $25 \mathrm{~m}^{3}$ room & {$[46]$} \\
\hline $\mathrm{d}, \mathrm{d}$-T-plarethrin & $0.20 \%$ & Stegomyia (Aedes) aegypti & 0.3 & 85 & $25 \mathrm{~m}^{3}$ room & {$[46]$} \\
\hline $\mathrm{d}, \mathrm{d}$-T-plarethrin & $0.10 \%$ & Culex pipiens pallens & 0.36 & 20.6 & $25 \mathrm{~m}^{3}$ room & [46] \\
\hline $\mathrm{d}, \mathrm{d}$-T-plarethrin & $0.15 \%$ & Culex pipiens pallens & 0.39 & 14 & $25 \mathrm{~m}^{3}$ room & {$[46]$} \\
\hline d,d-T-plarethrin & $0.15 \%$ & Culex pipiens quinquefasciatus & 0.47 & 100 & $25 \mathrm{~m}^{3} \mathrm{room}$ & [46] \\
\hline d,d-T-plarethrin & $0.20 \%$ & Culex pipiens quinquefasciatus & 0.5 & 63 & $25 \mathrm{~m}^{3}$ room & {$[46]$} \\
\hline $\mathrm{d}, \mathrm{d}$-T-plarethrin & $0.10 \%$ & Culex pipiens pallens & 0.51 & 14.5 & $25 \mathrm{~m}^{3}$ room & [46] \\
\hline d,d-T-plarethrin & $0.15 \%$ & Culex pipiens pallens & 0.53 & 11.4 & $25 \mathrm{~m}^{3}$ room & [46] \\
\hline d,d-T-plarethrin & $0.15 \%$ & Culex pipiens quinquefasciatus & 0.55 & 42 & $25 \mathrm{~m}^{3}$ room & {$[46]$} \\
\hline d,d-T-plarethrin & $0.20 \%$ & Culex pipiens pallens & 0.67 & 13.1 & $25 \mathrm{~m}^{3}$ room & [46] \\
\hline d,d-T-plarethrin & $0.20 \%$ & Culex pipiens quinquefasciatus & 0.71 & 24 & $25 \mathrm{~m}^{3}$ room & [46] \\
\hline d,d-T-plarethrin & $0.10 \%$ & Anopheles dirus & 0.91 & 8 & $25 \mathrm{~m}^{3}$ room & [46] \\
\hline $\mathrm{d}, \mathrm{d}$-T-plarethrin & $0.10 \%$ & Anopheles dirus & 0.91 & 8 & $25 \mathrm{~m}^{3}$ room & {$[46]$} \\
\hline $\mathrm{d}, \mathrm{d}$-T-plarethrin & $0.20 \%$ & Culex pipiens pallens & 0.92 & 10.3 & $25 \mathrm{~m}^{3}$ room & {$[46]$} \\
\hline d,d-T-plarethrin & $0.20 \%$ & Anopheles dirus & 1 & 8.1 & $25 \mathrm{~m}^{3}$ room & [46] \\
\hline dl,d-T80 allethrin & $0.27 \%$ & Culex pipiens quinquefasciatus & 0.04 & 196 & $25 \mathrm{~m}^{3}$ room & {$[46]$} \\
\hline
\end{tabular}


Table 2 Knock-down time and mortality of mosquitoes after exposure to smoke from smoldering coils (Continued)

\begin{tabular}{|c|c|c|c|c|c|c|}
\hline dl,d-T80 allethrin & $0.27 \%$ & Stegomyia (Aedes) aegypti & 0.15 & 361 & $25 \mathrm{~m}^{3}$ room & {$[46]$} \\
\hline dl,d-T80 allethrin & $0.27 \%$ & Culex pipiens pallens & 0.2 & 28.3 & $25 \mathrm{~m}^{3}$ room & [46] \\
\hline dl,d-T80 allethrin & $0.27 \%$ & Stegomyia (Aedes) aegypti & 0.21 & 174 & $25 \mathrm{~m}^{3}$ room & [46] \\
\hline dl,d-T80 allethrin & $0.27 \%$ & Culex pipiens pallens & 0.27 & 18.6 & $25 \mathrm{~m}^{3}$ room & {$[46]$} \\
\hline dl,d-T80 allethrin & $0.50 \%$ & Culex pipiens pallens & 0.28 & 20.8 & $25 \mathrm{~m}^{3}$ room & {$[46]$} \\
\hline dl,d-T80 allethrin & $0.50 \%$ & Stegomyia (Aedes) aegypti & 0.29 & 170 & $25 \mathrm{~m}^{3}$ room & {$[46]$} \\
\hline dl,d-T80 allethrin & $0.27 \%$ & Culex pipiens quinquefasciatus & 0.35 & 41 & $25 \mathrm{~m}^{3} \mathrm{room}$ & [46] \\
\hline dl,d-T80 allethrin & $0.50 \%$ & Culex pipiens quinquefasciatus & 0.55 & 72 & $25 \mathrm{~m}^{3}$ room & {$[46]$} \\
\hline dl,d-T80 allethrin & $0.27 \%$ & Anopheles dirus & 1 & 11.1 & $25 \mathrm{~m}^{3}$ room & [46] \\
\hline dl,d-T80 allethrin & $0.50 \%$ & Anopheles dirus & 1 & 8 & $25 \mathrm{~m}^{3}$ room & {$[46]$} \\
\hline d-trans allethrin & $0.30 \%$ & Culex pipiens pallens & 0.18 & 3.9 & $70 \mathrm{~cm}^{3}$ Chamber & [44] \\
\hline d-trans allethrin & $0.30 \%$ & Stegomyia (Aedes) aegypti & 0.8 & 2.5 & $70 \mathrm{~cm}^{3}$ Chamber & [44] \\
\hline d-trans allethrin & $0.30 \%$ & Anopheles stephensi & 1 & 2.5 & $70 \mathrm{~cm}^{3}$ Chamber & [44] \\
\hline Esbiothrin & $1.00 \%$ & Stegomyia (Aedes) aegypti & 0.301 & 1.14 & $2 m^{3}$ Peet-Grady chamber & [45] \\
\hline Esbiothrin & $1.00 \%$ & Culex quinquefasciatus & 0.755 & 0.81 & $2 \mathrm{~m}^{3}$ Peet-Grady chamber & [45] \\
\hline Esbiothrin & $1.00 \%$ & Anopheles stephensi & 0.897 & 1.68 & $2 \mathrm{~m}^{3}$ Peet-Grady chamber & {$[45]$} \\
\hline Pyrethrin & $0.30 \%$ & Culex pipiens pallens & 0.12 & 8.8 & $70 \mathrm{~cm}^{3}$ Chamber & [44] \\
\hline Pyrethrin & $0.30 \%$ & Anopheles stephensi & 0.31 & 5.2 & $70 \mathrm{~cm}^{3}$ Chamber & [44] \\
\hline Pyrethrin & $0.30 \%$ & Stegomyia (Aedes) aegypti & 0.46 & 5.5 & $70 \mathrm{~cm}^{3}$ Chamber & [44] \\
\hline S-d- t -allethrin & $0.15 \%$ & Culex pipiens pallens & 0.22 & 3.6 & $70 \mathrm{~cm}^{3}$ Chamber & [44] \\
\hline S-d- t -allethrin & $0.15 \%$ & Stegomyia (Aedes) aegypti & 0.87 & 2.5 & $70 \mathrm{~cm}^{3}$ Chamber & [44] \\
\hline S-d- t -allethrin & $0.15 \%$ & Anopheles stephensi & 0.88 & 2.7 & $70 \mathrm{~cm}^{3}$ Chamber & [44] \\
\hline Terallethrin & $0.15 \%$ & Culex pipiens pallens & 0.38 & 2.8 & $70 \mathrm{~cm}^{3}$ Chamber & [44] \\
\hline Terallethrin & $0.15 \%$ & Stegomyia (Aedes) aegypti & 0.59 & 1.8 & $70 \mathrm{~cm}^{3}$ Chamber & [44] \\
\hline Terallethrin & $0.15 \%$ & Anopheles stephensi & 0.73 & 1.7 & $70 \mathrm{~cm}^{3}$ Chamber & [44] \\
\hline
\end{tabular}

indicated that guinea pigs underestimated reduction in biting inhibition [42]. This is because guinea pigs do not produce sufficient heat, moisture and carbon dioxide and have a different composition of head space kairomones hence do not attract anthropophilic mosquitoes as much as humans. We propose conducting HLC evaluations inside semi-field systems (SFS) using laboratory reared disease-free mosquitoes to reflect the end use of spatial repellents, while protecting participants from potential exposure to disease carrying mosquitoes.

\section{Knock-down and mortality}

Knocked-down (KD) is the incapacitation of mosquitoes after contact with a sub-lethal dose of insecticide [43] resulting in the inability of the insect to maintain normal posture or fly.

High concentrations of pyrethrins induce faster KD50 (within 3-5 minutes of exposure) followed by high mortality rate while low concentrations induce slower KD50 (more than 10 minutes after exposure) indicating a dose-response relationship (Table 2). It is also important to note that coils induce up to $95 \%$ mortality in laboratory-assays compared to very low levels observed in field-assays (3\%-16\%) (Table 2). This is attributed to volume and/or ventilation limitations that may occur in some laboratory assay spaces, which reduce insecticide dispersion consequently increasing relative insecticide concentration.

Optimized metofluthrin emanators induce 100\% KD of mosquitoes within 30 minutes of exposure followed by $100 \%$ mortality within 24 hours in the laboratory [28]. We did not find any studies that demonstrated correlation between dose and response of mosquitoes to emanators. However, Kawada et al. reported that caged mosquitoes placed immediately near metofluthrintreated paper strips showed 100\% KD within 30 minutes and $100 \%$ mortality 24 -hours post-exposure, while mosquitoes placed $1.5 \mathrm{~m}$ away from the strip had slower $\mathrm{KD}$ and $70 \%$ mortality and mosquitoes placed $5 \mathrm{~m}$ away were unaffected [28]. This could be attributed to decreasing concentration of airborne active ingredients as one moved away from the source. It is noteworthy that these results may not be representative of natural conditions because mosquitoes are confined within the cage thus are likely to take up more active compared to when they are free flying.

The intensity of KD and mortality of mosquitoes is largely dependent on release and degradation rates of 
actives, initial loading dose on substrate and environmental conditions.

\section{Harmonization in methodologies for testing spatial mosquito repellents}

To characterize behavioural endpoints of mosquitoes exposed to chemical emanations of coils and emanators through rigorous independent and repeatable tests, it is essential to harmonize methodologies used.

\section{Mosquito species}

The mosquito species selected for bioefficacy studies is dependent on the objective and medical importance of a particular species in a given study area. The World Health Organization (WHO) recommends use of Stegomyia (Aedes) aegypti and Culex quinquefasciatus for testing household-insecticides [19]. Evaluations should be conducted on both susceptible and resistant strains of different mosquito species. Different mosquito genera, species, and population strains of the same species, vary in their susceptibility to insecticide due to specific selection pressures at site of origin and this can bias the intensity of outcome measures (Table 1). Consequently, we recommend that, when available, mosquito test populations should be acquired from disease endemic areas for which the chemical actives are intended to be used.

\section{Size of the laboratory test chambers or rooms}

Field and laboratory studies are conducted in chambers, cylinders, rooms or huts of different sizes (Table 2). Mosquitoes are knocked-down faster in cylinders or small chambers compared to large rooms $\left(25 \mathrm{~m}^{3}\right)$ [42]. This is attributed to low aerial concentration of chemical actives in large ventilated rooms. Peet-Grady chambers [19] are good alternatives to air-tight cylinders. These chambers have improved ventilation provided by built-in fans and a larger volume $(180 \mathrm{~cm}$ by $180 \mathrm{~cm}$ by $180 \mathrm{~cm})$ [19]. Tests carried out in Peet-Grady chambers and large rooms demonstrated that KD time was relatively shorter in the chambers than in the rooms [42]. Despite these limitations, cylinders/chambers or small rooms enable precise measurement of mosquito responses to various doses of chemical actives and generation of dose response curves. This might not be possible in field settings where external environmental factors such as wind speed and direction are likely to influence efficacy of the spatially acting actives. Cylinders or small chambers should be used primarily during initial screening for actives. Subsequent studies should then be conducted in more natural environments such as experimental huts and semi-field systems.

\section{Environmental factors}

The spatial activity of airborne insecticide is dependent on airflow (i.e., air exchange), wind speed, temperature and humidity within the treated space [47]. The greater the air current, the greater the insecticidal dispersion over a specified area followed by reduced insecticide concentration accompanied by dilution of chemical attractants from the human thus reduced host attack by mosquitoes [48]. A study carried out in Tanzania demonstrated reduced efficacy of emanators when used in houses with open eaves [25] compared to houses which did not have eaves in Vietnam [47]. It is necessary to consider the degree of ventilation of the test structure and average environmental conditions during peak disease transmission seasons within the test area where the spatial repellent will be used. High temperature, increases evaporation rate of active ingredient [47] which may improve efficacy but can also lead to faster loss of actives followed by reduced efficacy over time. Therefore, it is necessary to determine the rate at which chemical actives are released from coils and emanators under different environmental conditions in order to determine how much repellent active ingredient will be required for efficacy over time.

\section{Experimental design}

Other factors affecting experimental outcomes include sample size, which may refer to the number of people used in the trial or number of mosquitoes used and the number of replicates performed during evaluations. It is necessary to determine the number of mosquitoes required for a representative sample. This also applies to the number of human subjects required to account for differences in individual attractiveness to mosquitoes [49-51]. Wherever possible, a balanced Latin Square or William's Square design with rotation of volunteers and or treatments is desirable. We recommend analysis with generalised linear mixed models [52] which account for over-dispersed nature of repellent mosquito data when variance is greater than mean due to variability caused by the great variability among experimental days [53]. Few of the studies reviewed used appropriate study design or analyses. We propose that future studies report means with standard errors or confidence intervals, or medians with the inter-quartile range in addition to test statistics. This information was not given by most of the studies reviewed, thus, we were unable to conduct a meta-analysis.

\section{Conclusion}

Spatial repellents is the general term used to describe delivery formats such as coils, mats and passive emanators which release vaporised chemical actives capable of affecting mosquito behaviour at a distance. Most vapour 
chemical actives also knock down, kill or inhibit feeding of mosquitoes. General use of this term causes confusion especially where oriented movement away from the chemical source is not demonstrated. For purposes of clarity we propose that spatial repellency should be used as a general term to refer to sum of mosquito behaviours induced by airborne chemicals that cause mosquitoes to sit apart from a source of stimulation. Despite differences in evaluation methodologies, coils and emanators clearly reduce human-mosquito contact. They induce mortality, deterrence, repellency and reduce feeding of mosquitoes on humans. Mortality was the least observed effect where tests were conducted in experimental huts. This shows that these products do not kill mosquitoes in natural settings with free air movements and therefore may not affect overall mosquito densities or contribute to "community effect" as other toxic insecticides would.

Mosquito coils increased the proportion of mosquitoes exiting huts. It is not clear whether mosquitoes leave treated houses because they are unable to locate hosts for blood meals and therefore continue searching for other blood sources or whether they leave because they are irritated by chemicals in the smoke/vapour and are forced to escape. This needs more investigation.

Reduction in human-vector contact through feeding inhibition is likely to have an epidemiologically significant effect because of reduced risk of getting infectious mosquito bites. Any reduction in human-biting rate of mosquitoes is likely to lower vectorial competence of vectors and affect the lifetime fecundity of vectors which will in turn influence the basic reproductive rate of any parasites that they transmit. In addition to the measure of chemically induced feeding inhibition, it is necessary to conduct studies that quantify fecundity in order to see whether reduced blood feeding consequently reduces fertility of mosquitoes and leads to an overall reduction of mosquito population.

There is minimal data available on dose-response relationships, effective distance and residual efficacy of treated materials. However, the data reviewed here indicate that feeding inhibition, knockdown and mortality are positively influenced by high doses of active ingredient while deterrence does not change with change in dose. However, other studies indicate that deterrence resulting from DDT residues inside huts diminishes with time as the active ingredient degrades [3], indicating a dose dependent-response relationship. Unfortunately, there was no evidence from testing coils and emanators, hence there is need to conduct studies to ascertain this for different doses of coils and emanators under outdoor conditions.

It is hypothesized that since spatial repellents do not kill mosquitoes, there is increased risk of unprotected people being infected with pathogens transmitted by mosquitoes diverted from repellent users [54]. Therefore it is necessary to determine the distance at which nonusers are at increased risk of receiving more mosquito bites for repellent-specific actives. On the other hand, non-users may in fact be protected due to airborne dispersion of volatized chemicals. In addition, it is also worthwhile to understand whether feeding inhibition of mosquitoes can be prolonged over several hours or days through product optimization, as this is an epidemiologically significant endpoint for arthropod-borne diseases.

A meta-analysis could not be conducted as a result of the differences in evaluation methodologies as well as minimal statistical parameters reported by various studies. Hence, we strongly underline the need to reach consensus in spatial repellent testing methodologies and data reporting facilitated through the development of standardized assay guidelines. It is important to note that it is highly likely that additional data on spatial repellents has been gathered but not made available to the scientific community. Publication bias due to industry-associated research may contribute to missing data sets, which if shared could greatly contribute to better characterization of spatial repellents. This information is vital for the development of standardized testing methodologies as well as target product profiles. Therefore scientists in industry are encouraged to share their data which will aid this process.

Spatial repellents have the potential to become an important component of vector control since outdoor biting vectors are gaining importance as malaria vectors [55]. In order to understand the dynamics of these products and their potential for vector control programs it is necessary to comprehensively characterize their mode of action (i.e., physiological pathways/receptors and behavioural modification involved in insect response) using standardized methodologies to facilitate the development of a target product profile (TPP) and testing of candidate products so that the required information on their efficacy in disease prevention can be more rapidly collected and policy makers better informed for maximum effective benefit in disease control.

\section{Competing interests}

The authors declare that they have no competing interest.

\section{Authors' contribution}

SBO conducted the review and drafted the manuscript. SBO, SJM and MFM wrote the final version of the manuscript. All authors read and approved the final manuscript.

Acknowledgements

This study was funded by the Bill \& Melinda Gates Foundation through award number 51431.

Received: 18 April 2012 Accepted: 29 November 2012

Published: 7 December 2012 


\section{References}

1. Steketee RW, Campbell CC: Impact of national malaria control scale-up programmes in Africa: magnitude and attribution of effects. Malar J 2010, 9:299.

2. Gillies MT, Smith A: Effect of a residual house-spraying campaign on species balance in the Anopheles funestus group: The replacement of Anopheles gambiae Giles with Anopheles rivulorum Leeson. Bull Entomol Res 1960, 51:248-252.

3. Smith A, Webley DJ: A verandah trap for studying the house-frequenting habits of mosquitoes and for assessing insecticides. Part III. The effect of DDT on behaviour and mortality. Bull Entomol Res 1968, 59:33-46.

4. Grieco JP, Achee NL, Chareonviriyaphap T, Suwonkerd W, Chauhan K, Sardelis MR, Roberts DR: A new classification system for the actions of IRS chemicals traditionally used for malaria control. PLoS One 2007, 716:e716.

5. Sadasivaiah S, Tozan Y, Breman JG: Dichlorodiphenyltrichloroethane (DDT) for indoor residual spraying in Africa: how can it be used for malaria control? Am J Trop Med Hyg 2007, 77:249-263.

6. Roberts DR, Tren R, Bates R, Zambone J: The excellent powder: DDT's political and scientific history. Indianapolis: Dog ear publishing. LLC; 2010

7. Dethier GV, Browne BL, Smith NC: The designation of chemicals in terms of the responses they elicit from insects. J Econ Ento 1960, 53:134-136.

8. Miller JR, Siegert PY, Amimo FA, Walker ED: Designation of chemicals in terms of the locomotor responses they elicit from insects: an update of Dethier et al. (1960). J Econ Entomol 2009, 102:2056-2060.

9. Roberts DR: Insecticide repellency in malaria vector control. A position paper. Arlington Va: VBC Project Tropical Disease Control for Development; 1993.

10. Smyth T, Roys CC: Chemoreception in insects and the mode of action of DDT. Biol Bull 1955, 108:66-76.

11. Kennedy JS: The excitant and repellent effects on mosquitoes of sublethal contacts with DDT. Bull Entomol Res 1947, 37:593-607.

12. Miller JE, Lindsay SW, Armstrong JR: Experimental hut trials of bednets impregnated with synthetic pyrethroid or organophosphate insecticide for mosquito control in The Gambia. Med Vet Entomol 1991, 5:465-476.

13. Adams ME, Miller TA: Neural and behavioral correlates of pyrethroid and DDT-type poisoning in the house fly, Musca domestica L. Pesticide Biochem Physiol 1980, 13:137-147.

14. Ranson H, Jensen B, Vulule JM, Wang X, Hemingway J, Collins FH: Identification of a point mutation in the voltage-gated sodium channel gene of Kenyan Anopheles gambiae associated with resistance to DDT and pyrethroids. Insect Mol Biol 2000, 9:491-497.

15. Haynes KF: Sublethal effects of neurotoxic insecticides on insect behaviour. Ann Rev Entomol 1988, 33:149-168.

16. McMahon C, Krober T, Guerin PM: In vitro assays for repellents and deterrents for ticks: differing effects of products when tested with attractant or arrestment stimuli. Med Vet Entomol 2003, 17:370-378,

17. Kaupp UB: Olfactory signalling in vertebrates and insects: differences and commonalities. Nat Rev Neurosci 2010, 11:188-200.

18. Bohbot JD, Fu L, Le TC, Chauhan KR, Cantrell CL, Dickens JC: Multiple activities of insect repellents on odorant receptors in mosquitoes. Med Vet Entomol 2011, 25:436-444.

19. WHO: Guidelines for efficacy testing of household insecticides products Mosquito coils, vaporizer mats, liquid vaporizers, ambient emanators and aerosols. (WHO ed., vol. 3. Geneva: WHO/NTD/WHOPES; 2009.

20. Bill and Melinda Gates Foundation and Boston Consulting Group: Market Assessment for Public Health Pesticide Products. Boston: Boston Consulting Group; 2007.

21. Griffin JT, Hollingworth TD, Okell LC, Churcher TS, White M, Hinsley W, Bousema T, Drakeley CJ, Ferguson HM, Basanez MG, Ghani AC: Reducing Plasmodium falciparum malaria transmission in Africa: a model-based evaluation of intervention strategies. PLOS Med 2010, 7:8.

22. Malera T: A research agenda for malaria eradication: vector control. PLoS Med 2011, 8:e1000401.

23. Liu WK, Wong MH, Mui YL: Toxic effects of mosquito coils (a mosquito repellent) smoke on rats 1. Properties of the mosquito coil and its smoke. Toxicol Lett 1987, 39:223-230.

24. Argueta BT, Kawada H, Takagi M: Spatial repellency of metofluthrinimpregnanted multilayer paper strip against Aedes albopictus under outdoor conditions, Nagasaki, Japan. Med Entomol Zool 2004, 55:211-216.

25. Kawada H, Temu EA, Minjas NJ, Matsumoto O, Iwasaki T, Takagi M: Field evaluation of spatial repellency of metofluthrin-impregnated plastic strips against Anopheles gambiae complex in Bagamoyo, Coastal Tanzania. J Am Mosa Control Assoc 2008, 24:404-409.

26. Liberati A, Altman DG, Tetzlaff J, Mulrow C, Gøtzsche PC, Loannidis JPA, Clarke M, Devereaux PJ, Kleijnen J, Moher D: The PRISMA statement for reporting systematic reviews and meta-analyses of studies that evaluate health care interventions: explanation and elaboration. PLoS Med 2009, 6:7.

27. Pal R: Methods for studying the behaviour of malaria vectors under the impact of residual insecticides. Geneva: WHO; 1964.

28. Kawada H, Maekawa Y, Tsuda Y, Takagi M: Laboratory and field evaluation of spatial repellency with metofluthrin-impregnated paper strip against mosquitoes in Lombok Island, Indonesia. J Am Mosa Control Assoc 2004, 20:292-298.

29. Smith A, Hudson EJ, Esozed S: Trials with pyrethrum mosquito coils against Anopheles gambiae Gillies, Mansonia uniformis Theo. and Culex fatigans Wied. entering verandah-trap huts. Pyreth Post 1972, 11:111-115.

30. Browne LB: Host related responses and their suppression: some behavioural considerations. Behaviour: Chemical Control of Insect; 1977.

31. Achee LN, Sardelis MR, Dusfour I, Chauhan KR, Grieco JP: Characterization of spatial repellent, contact irritant, and toxicant chemical actions of standard vector control compounds. J Am Mosa Control Assoc 2009, 25:156-167.

32. Wirtz RA, Turrentine JD, Fox RC: Area repellents for mosquitoes (Diptera: Culicidae): identification of the active ingredients in a petroleum oil fraction. J Med Entomol 1981, 18:126-128.

33. Hudson EJ, Esozed S: The effect of smoke from mosquito coils on Anopheles gambiae Gillies and Mansonia uniformis (Theo.) in verandahtrap huts at Magugu, Tanzania. Bull Ent Res 1971, 61:247-265.

34. Mosha WF, Njau RJA, Alfred J: Efficacy of esbiothrin mosquito coils at community level in nothern Tanzania. Med Vet Entomol 1992, 6:44-46.

35. Mosha WF, Njau RJA, Myamba J: Biological efficacy of new formulations of mosquito coils and a critical review of test methods. Pyreth Post 1989, 2:47-52.

36. Siegert PY, Walker E, Miller JR: Differential behavioral responses of Anopheles gambiae (Diptera: Culicidae) modulate mortality caused by pyrethroid-treated bednets. J Econ Entomol 2009, 102:2061-2071.

37. Bohbot JD, Dickens JD: Insect repellents: modulators of mosquito odorant receptor activity. PLoS One 2010, 5:e12138.

38. Hao H, Wei J, Dai J, Du J: Host-seeking and blood-feeding behavior of Aedes albopictus (Diptera:Culicidae) exposed to vapors of geraniol, citral, citronellal, eugenol or anisaldehyde. J Med Entomol 2008, 45:533-539.

39. Lucas JR, Shono Y, Iwasaki T, Ishiwatari T, Spero N: Field evaluation of metofluthrin- A new mosquito repellent. In Fifth International Conference on Urban Pests; Malaysia. Edited by Robinson C-YLWH. Malaysia: Perniagaan Ph'ng @ P and Y Design New York; 2005.

40. Birley MH, Mutero CM, Turner IT, Chadwick PR: The effectiveness of mosquito coils containing esbiothrin under laboratory and field conditions. Ann Trop Med Parasitol 1987, 81:163-171.

41. WHOPES: Guidelines for efficacy testing of mosquito repellents for human skin vol. 4. Geneva: World Health Organisation; 2009.

42. Chadwick PR: The activity of some pyrethroids, DDT and lindane in smoke from coils for biting inhibition, knock down and kill of mosquitoes (Diptera, Culicidae). Bull ento Res 1975, 67:97-101.

43. White GB: Terminology of insect repellents. In Insect repellents Principles, Methods and Uses. Edited by Debboun M, Frances SP, Strickman D. Boca Raton: CRC Press Taylor and Francis Group; 2007.

44. Yamaguchi T, Shinjo G, Tsuda S, Yoshida K, Inaba E, Okuno Y: Insecticidal activity of a new synthetic pyrethroid. Japan J Sanit Zool 1981, 32:59-66.

45. Amalraj DD, Sivagnaname N, Boopathidoss PS, Das PK: Bioefficay of mosquito mats, coils and dispenser formulations, containing allethrin group of synthetic pyrethroids against mosquito vectors. $J$ Commun Dis 1996, 28:85-93.

46. Katsuda Y, Leemingsawat S, Thongrungkiat S, Komalamisara N, Kanzaki T, Watanabe T, Kahara T: Control of mosquito vectors of tropical infectious diseases: (1) Bioefficacy of mosquito coils containing several pyrethroids and a synergist. Southeast Asian J Trop Med Public Health 2008, 39:48-54.

47. Kawada H, Iwasaki T, Loan LL, Tien TK, Mai NTN, Shono Y, Katayama Y, Takagi M: Field evaluation of spatial repellency of metofluthrinimpregnated latticework plastic strips against Aedes aegypti (L.) and analysis of environmental factors affecting its efficacy in My Tho City, Tien Giang, Vietnam. Am J Trop Med Hyg 2006, 75:1153-1157. 
48. Hoffmann EJ, Miller JR: Reduction of mosquito (Diptera: Culicidae) attacks on a human subject by combination of wind and vapor-phase DEET repellent. J Med Entomol 2002, 39:935-938.

49. Brady J, Constantini C, Sagnon N, Gibson G, Coluzzi M: The role of body odours in the relative attractiveness of different men to malaria vectors in Burkina Faso. Ann Trop Med Parasitol 1997, 91:121-122.

50. Lindsay SW, Adiamah JH, Miller JE, Pleass RJ, Armstrong JRM: Variation in the attractiveness of human subjects to malaria mosquitoes (Diptera: Culicidae) in The Gambia. J Med Entomol 1993, 30:368-373.

51. Mukabana RW, Takken W, Coe R, Knols GJB: Host-specific cues cause differential attractiveness of Kenyan men to the African malaria vector Anopheles gambiae. Malar J 2002, 1.

52. Chaves LF: An entomologist guide to demystify pseudoreplication: data analysis of field studies with design constraints. J Med Entomol 2010, 47:291-298.

53. Bolker BM, Brooks ME: Generalized linear mixed models: a practical guide for ecology and evolution. Trends Ecol Evol 2009, 24:127-135.

54. Moore SJ, Davies C, Cameron MM: Are mosquitoes diverted from repellent-using individuals to non-users? Results of a field study in Bolivia. Trop Med Int Health 2007, 12:1-8.

55. Reddy M, Overgaard HJ, Abaga S, Reddy VP, Caccone A, Kiszewski A, Slotman MA: Outdoor host seeking behavior of Anopheles gambiae mosquitoes following initiation of malaria vector control on Bioko Island, Equitorial Guinea. Malar J 2011, 10:184.

\section{doi:10.1186/1756-3305-5-287}

Cite this article as: Ogoma et al:: A systematic review of mosquito coils and passive emanators: defining recommendations for spatial repellency testing methodologies. Parasites \& Vectors 2012 5:287.

\section{Submit your next manuscript to BioMed Central and take full advantage of:}

- Convenient online submission

- Thorough peer review

- No space constraints or color figure charges

- Immediate publication on acceptance

- Inclusion in PubMed, CAS, Scopus and Google Scholar

- Research which is freely available for redistribution 